\title{
Intradisciplinaridade Matemática com GeoGebra na Matemática \\ Escolar
}

\section{Mathematical Intradisciplinarity with GeoGebra in School Mathematics}

\author{
Rejane Waiandt Schuwartz de Carvalho Faria * \\ ORCID iD 0000-0002-2422-969X \\ Marcus Vinicius Maltempi ${ }^{* *}$ \\ ORCID iD 0000-0001-5201-0348
}

\begin{abstract}
Resumo
Neste artigo discutimos o trabalho intradisciplinar na Matemática escolar e trazemos evidências de que o uso do GeoGebra o favorece. Para tanto, questionamos o processo de disciplinarização da ciência, que contribuiu com o aprofundamento das diversas áreas, ao mesmo tempo em que impulsionou uma crescente dissociação entre elas. De igual modo, a hiper-especialização do saber matemático contribuiu para a fragmentação da Matemática escolar nas ramificações aritmética, geometria e álgebra, o que tem dificultado seu aprendizado pelos alunos. Buscando o equilíbrio entre fragmentação e totalização, investigamos a intradisciplinaridade da Matemática escolar com GeoGebra. A metodologia utilizada é de cunho qualitativo e aqui analisamos uma atividade de exploração do raciocínio proporcional, desenvolvida com professores de Matemática que atuavam nos Anos Finais do Ensino Fundamental. A análise indica que o GeoGebra oportuniza a exploração de múltiplas representações que destacam particularidades das ramificações matemáticas por meio de seus diversos recursos e janelas que apresentam os objetos matemáticos dinamicamente conectados, o que contribui para que as desvantagens de cada representação sejam supridas pelas vantagens das outras, no que se refere ao ensino e à aprendizagem de Matemática. Concluímos que a abordagem matemática intradisciplinar com GeoGebra ressalta o trabalho concomitante entre as diferentes ramificações matemáticas e oferece ao professor a possibilidade de explorá-lo em sua prática pedagógica.
\end{abstract}

Palavras-chave: Raciocínio Proporcional. Tecnologias Digitais. Educação Matemática.

\begin{abstract}
In this paper, we discuss the intradisciplinary work in school mathematics and bring evidences that the use of GeoGebra favors it. In order to do so, we question the process of disciplining science that contributed to the deepening of various areas, at the same time as it propelled a growing dissociation among them. Similarly, the hyper-specialization of mathematical knowledge has contributed to the fragmentation of school mathematics in the arithmetic, geometry, and algebra ramifications, which has made it difficult to learn by the students. Seeking the balance between fragmentation and totalization, we investigated the intradisciplinarity of school mathematics with GeoGebra. We used a qualitative research methodology and we analyzed an activity of proportional reasoning exploration developed with mathematics teachers from an elementary school. The analysis indicate that GeoGebra allows for the exploration of multiple representations that highlight particularities of the
\end{abstract}

\footnotetext{
* Doutora em Educação Matemática pela Universidade Estadual Paulista (UNESP), Rio Claro/SP. Diretora da Faculdade de Ciências da Universidade Federal do Pará (UFPA), Salinópolis, Pará. Endereço: Rua Raimundo Santana Cruz, s/nº, São Tomé, Salinópolis, Pará, Brasil, CEP: 68721-000. E-mail: rejanefaria@ufpa.br.

** Livre Docente em Educação Matemática pela Universidade Estadual Paulista (UNESP), Rio Claro/SP. Professor do Programa de Pós-Graduação em Educação Matemática e do Departamento de Estatística, Matemática Aplicada e Computação da Universidade Estadual Paulista (UNESP), Rio Claro/SP. Endereço: Avenida 24A, 1515, Bela Vista, Rio Claro, São Paulo, Brasil, CEP 13506-900. E-mail: maltempi@rc.unesp.br.
} 
mathematical fronts through its diverse resources and windows that present the dynamically connected mathematical objects, which contributes in a way that the disadvantages of each representation are satisfied by the advantages of the others in teaching and learning mathematics. We concluded that the intradisciplinary mathematical approach with GeoGebra emphasizes the concomitant work among the different mathematical ramifications and offers the teachers the possibility of exploring it in their pedagogical practice.

Keywords: Proportional Reasoning. Digital Technologies. Mathematical Education.

\section{Introdução}

A educação escolar foi organizada em disciplinas nas primeiras instituições escolares no Brasil com os jesuítas no século XVI. Desde então, essa educação tem tido um caráter cada vez mais compartimentalizado em disciplinas, de modo que a especialização do saber tem levado professores a terem uma formação mais profunda e, ao mesmo tempo, mais restrita a uma área científica.

Certamente, a sociedade tem muito a ganhar com a especialização profissional em áreas, pois ao concentrar seus esforços em uma ramificação de um campo científico, é mais provável que se consiga aprofundar em uma temática, o que favorece o desenvolvimento das mais diversas ciências. Por outro lado, a divisão em disciplinas estabelece fronteiras com linguagem e conceitos próprios, que podem levar um conhecimento a se isolar dos demais e dos questionamentos capazes de colocá-lo em movimento e que poderiam contribuir para a evolução de outras ciências e disciplinas (MORIN, 2000).

Esse processo de compartimentalização do saber foi além dos agrupamentos em disciplinas como Geografia, Química, Física, Matemática, dentre outras. Ele também contribuiu para a fragmentação das disciplinas em ramificações cada vez mais especializadas. A Matemática escolar, especificamente, é composta atualmente de aritmética, geometria e álgebra, de um modo que essas ramificações têm sido apresentadas como subáreas que possuem poucas conexões entre si. Assim como ocorre com a disciplinarização da ciência, na Matemática também se percebe ganhos e perdas com a dissociação entre suas vertentes. Se, por um lado, esse processo tem permitido um aprimoramento na linguagem, nos processos, nos métodos, nos códigos, nos princípios e em outras especificidades da aritmética, da geometria e da álgebra, por outro, certamente tem dificultado o entendimento das conexões entre elas.

Buscando o equilíbrio entre fragmentação e totalização, propomos a abordagem concomitante de aritmética, geometria e álgebra no software GeoGebra. Assim, este artigo objetiva discutir o trabalho intradisciplinar na Matemática escolar e trazer evidências de que o 
uso do GeoGebra o favorece. Com esse intuito, apresentamos neste artigo uma atividade de desenvolvimento e exploração do raciocínio proporcional ${ }^{1}$ que foi aprimorada por meio da interação com professores de Matemática que atuavam nos Anos Finais do Ensino Fundamental.

\section{Disciplinarização da ciência}

Desde o primeiro século de colonização do Brasil, a educação escolar tem sido disposta em disciplinas (MIRANDA, 2003). Mas antes mesmo de chegar ao Brasil nesse formato com os portugueses, o que teria motivado a divisão do conhecimento produzido em disciplinas nas mais diversas partes do planeta? Quais foram os critérios usados para agrupar o conhecimento científico em áreas tão específicas do saber?

Segundo Gallo (2000, p. 21) "nas sociedades antigas, a produção do conhecimento fazia-se em resposta às necessidades de explicação de uma realidade misteriosa que era experimentada no dia-a-dia, [...] levando-os a formular questões fundamentais em torno do sentido da vida e do universo". Essas explicações não eram atribuídas às disciplinas específicas, eram relativas às necessidades fisiológicas e intelectuais da humanidade, que permitiam avançar com respostas dadas às antigas perguntas e à formulação de novos questionamentos sobre a "religiosidade, engenhosidade e praticidade" (GALLO, 2000, p. 21).

É interessante perceber que as observações e as constatações iniciais, que fomentaram o desenvolvimento da ciência, surgiram e foram exploradas a partir de um mesmo fenômeno de interesse, como descrito no exemplo a seguir.

[...] ao surgir a astronomia, a observação sistemática dos astros no céu, aparecia a
necessidade de medir seus movimentos, metrificá-los, dando maior impulso à
matemática e à geometria; a explicação dos movimentos que ocorriam na Terra e no
Universo levavam a física a maiores avanços na matemática, e assim
sucessivamente. Com o crescente acúmulo do saber, entretanto, foi ocorrendo uma
especialização cada vez mais radical: um físico, por exemplo, é cada vez menos um
matemático, no sentido de que não mais estuda a matemática em si mesma - como
um Newton contemporâneo - mas apenas se utiliza dos processos matemáticos já
existentes para poder equacionar as questões teóricas com que trabalha na física.
(GALLO, 2000, p. 21-22).

De igual modo, acontece em outras áreas. Isso está ligado ao fenômeno da especialização do saber que ocorre por estarmos, como sociedade, formando pesquisadores

${ }^{1} \mathrm{O}$ raciocínio proporcional está relacionado com formas de raciocínio, reações diante de situações proporcionais ou não proporcionais, desenvolvimento e aprimoramento de habilidades e aptidões concernentes à lógica necessária ao raciocínio matemático (LAMON, 2005). Em Faria (2016, p. 49) é explicitado que ele pode ser entendido como "[...] a capacidade de raciocinar, estabelecendo uma relação entre duas ou mais grandezas em termos relativos, mobilizando para tal raciocínio a habilidade de analisar qualitativamente situações, estabelecer relações, julgar com equidade e distinguir circunstâncias proporcionais das não proporcionais". 
cada vez mais centrados em um ramo compreendido em uma área de conhecimento (GALLO, 2000). Este fenômeno tem acarretado implicações na Educação. A divisão em disciplinas expõe o conhecimento “[...] ao risco de hiper-especialização do pesquisador e ao risco de ‘coisificação' do objeto estudado. Este, percebido como uma coisa em si, expõe-se a esquecer que é extraído ou construído" (MORIN, 2000, p. 67).

E o que há de perigo nisso? O que pode haver de ruim com a hiper-especialização? O que se tem a perder ao "coisificar" o objeto de estudo? O perigo maior está em romper conexões e distanciar os mais diversos objetos de estudo. A hiper-especialização pode levar à negligência do objeto com o seu contexto de origem. Mais especificamente, o processo de especialização do saber culmina para a dissociação entre as disciplinas escolares.

\begin{abstract}
Quando assiste a uma aula de história, cada aluno abre a gavetinha de seu arquivo mental onde guarda os conhecimentos históricos; ao final da aula, fecha essa gavetinha e abre aquela referente à matéria a ser estudada na próxima aula, e assim por diante... E como cada uma das "gavetinhas" é estanque, sem nenhuma relação com as demais, os alunos não conseguem perceber que todos os conhecimentos vivenciados na escola são perspectivas diferentes de uma mesma e única realidade, parecendo cada um deles autônomo e auto-suficiente, quando na verdade só pode ser compreendido em sua totalidade como parte de um conjunto, peça ímpar de um imenso puzzle que pacientemente montamos ao longo dos séculos e dos milênios (GALLO, 2000, p. 23).
\end{abstract}

É natural que, mesmo pertencendo a um conjunto científico maior, uma disciplina busque sua autonomia por meio da demarcação de suas fronteiras, o que inclui linguagem, técnicas e teorias próprias. Também não se pode negar que "graças às divisões e subdivisões do conhecimento, aquele conhecimento inicial e totalizador foi sendo aprofundado e ampliado, e por esse processo foram surgindo as diferentes áreas do conhecimento que, por sua vez, iam sendo ampliadas e aprofundadas" (ALVES; GARCIA, 2000, p. 83). Assim, dividir o conhecimento elaborado pela humanidade em ciências e em disciplinas escolares contribui para que as áreas sejam cada vez maiores em diversas dimensões.

Nesse sentido, não defendemos que as variadas áreas do conhecimento sejam fundidas, como foram outrora. Se isso ocorresse, certamente haveria perdas em amplitude e profundidade nos objetos de estudo. O que defendemos é que a ciência não deve ser dissociada, pois os mais diversos objetos de estudo, de alguma forma pertencem a um contexto maior, o do conhecimento humano. Para Morin (2000, p. 79), “este é o problema da disciplina, o problema da ciência, bem como o problema da vida: é preciso que uma disciplina seja, ao mesmo tempo, aberta e fechada".

Assim como ocorreu com a ciência em geral, sucedeu com a Matemática. Segundo D’Ambrosio (2008, p. 22), a "matemática é uma resposta à busca de sobrevivência e de transcendência, acumulada e transmitida ao longo de gerações, desde a pré-história”. Para 
sobreviver, o homem desenvolve técnicas e regras de comportamento que lhe permite ter acesso à água, aos alimentos, e a tudo o que é necessário para sobrevivência. Para transcender, desenvolve "[...] meios de explicar fatos e fenômenos, a percepção e o encadeamento do passado, presente e futuro" (D'AMBROSIO, 2008, p. 22). E nessa busca por sobreviver e transcender, diversas descobertas matemáticas emergiram e continuam a emergir, como técnicas de contar, calcular e medir, que configuram descobertas matemáticas, para as quais estratégias são criadas, organizadas intelectualmente, compartilhadas com o próximo pelos mais diversos meios de comunicação e organizadas socialmente de acordo com a necessidade e interesse dos povos.

Ao se especializar nas mais diversas ramificações que tangem a Matemática, pesquisadores vêm se aprofundando em temáticas que tem linguagem, regras e técnicas próprias. Todavia, essa realidade tem acarretado consequências para o ensino de Matemática, que tem sido cada vez mais dissociado e tem trazido implicações para a Matemática escolar.

\section{Intradisciplinaridade matemática}

A especialização do saber, o processo de disciplinarização do conhecimento, a hiperespecialização do pesquisador, a coisificação de um objeto de estudo, e outras questões ligadas à organização da ciência em disciplinas, nos tem levado a refletir sobre possíveis alternativas para uma educação escolar que considere a conexão entre diversos temas de estudo, o cotidiano dos alunos e que subsidie aspectos ligados tanto à sobrevivência quanto à transcendência humana de uma forma integradora. Segundo Morin (2000), não cabe mais tentar cancelar a ideia de organização da ciência, em lugar disso, é necessário compreender o conhecimento e reunir as disciplinas que foram compartimentalizadas.

Os processos de ensino e de aprendizagem de uma disciplina de forma isolada, sem relação com o que acontece nas outras disciplinas e no mundo, podem esconder uma armadilha, nomeada por D’Ambrosio (2011) de "gaiolas epistemológicas". Trata-se de uma metáfora criada para criticar o conhecimento aprisionado em uma disciplina assim como um pássaro preso em uma gaiola. Tais disciplinas são como gaiolas que possuem um conhecimento preso à sua fundamentação, aos seus métodos particulares para lidar com questões fechadas e com uma linguagem específica, fechada aos que não pertencem à certa área do conhecimento. Assim como não é possível saber a cor da gaiola por fora quando se está dentro dela, quando se está aprisionado a uma disciplina, a capacidade de compreensão fica limitada e dependente de práticas e metodologias definidas (D'AMBROSIO, 2011). 
É nesse sentido que o autor indica que transitar e estabelecer relações entre as disciplinas escolares, fenômeno chamado de interdisciplinaridade, é necessário. Ademais, é preciso ir além das disciplinas, fazendo com que os alunos avancem para realidades que ultrapassam os muros da escola, na perspectiva da transdisciplinaridade, pois esta "leva o indivíduo a tomar consciência da essencialidade do outro e da sua inserção na realidade [tendo como consequência] o despertar da consciência na aquisição do conhecimento" (D’AMBROSIO, 2011, p. 10). Para Morin (2000, p.79), “a transdisciplinaridade caracterizase muitas vezes por esquemas cognitivos que atravessam as disciplinas, às vezes com tal virulência que as colocam em sobressalto".

Mas além das ideias de inter e transdisciplinaridade, existe outra, que nos faz pensar nas "estritas relações das ramificações de uma mesma disciplina" (FARIA, 2016, p. 64), tratase da intradisciplinaridade. Segundo Lorenzato (2006, p. 60), “[...] se concordarmos com as vantagens do ensino interdisciplinar, com mais forte razão devemos professar o ensino intradisciplinar, o qual pode ser reduzido, sinteticamente, ao ensino de aritmética, geometria e álgebra”. O autor segue afirmando que ao fazermos isso, os alunos serão capazes de identificar a harmonia, coerência e beleza dos padrões matemáticos, mesmo sabendo que suas ramificações possuem peculiaridades.

Cabe esclarecer que a opção por apresentar a aritmética, a álgebra e a geometria como ramificações da Matemática se deu, pois essa é uma das formas que os conteúdos matemáticos da Educação Básica podem ser agrupados atualmente no Brasil (FARIA, 2016). Não negamos a existência de outras ramificações, como a trigonometria, a topologia, a combinatória, dentre outras. Apenas centramos os estudos neste trabalho nas três ramificações citadas, por entender que dessas que as demais se originam, como outras ramificações da Matemática na Educação Básica.

Corroboramos a ideia de que a geometria, a álgebra e a aritmética possuem o seu espaço dentro da Matemática, de modo que cada uma delas possui propriedades particulares, como vocabulário, simbologia, regras, conceitos e definições. Contudo, defendemos que tais propriedades sejam exploradas de forma simultânea nos processos de ensino e de aprendizagem da Matemática escolar.

Nesse sentido, a Matemática pode ser entendida como disciplina matriz, e a aritmética, geometria e álgebra como disciplinas derivadas, ou ainda, como ramificações da disciplina matriz. "É interessante que, ao termos coragem de romper com as fronteiras disciplinares, vamos encontrar respostas a nossas questões as quais, na fronteira disciplinar que alguns insistem em nos prender, não havíamos encontrado" (ALVES; GARCIA, 2000, p. 95). 
Segundo Lorenzato (2006), a intradisciplinaridade matemática pode ser um apoio para a aprendizagem, pois a conexão entre as ramificações da Matemática é capaz de facilitar a percepção dos significados dos conceitos, valorizar as semelhanças e eliminar a fragmentação das ideias, contribuindo assim para a ampliação da compreensão que permeia o entendimento dos assuntos matemáticos. Desse modo,

[...] defender a intradisciplinaridade não significa incentivar a abordagem da
disciplina matemática como uma gaiola epistemológica, que se preocupa apenas
com sua linguagem, regras e técnicas. O que a intradisciplinaridade propõe é que as
ramificações da matemática não estejam dissociadas, como se houvessem
subdisciplinas isoladas. Nesse sentido, embora a intradisciplinaridade proponha o
trabalho simultâneo entre os ramos da matemática, isso não significa que ela negue a
relação que deve haver entre essa disciplina e as outras que compóem o cenário
escolar (interdisciplinaridade). Tampouco consiste em uma negação da abordagem
que valoriza a matemática e o contexto que ultrapassa os muros da escola
(transdisciplinaridade) (FARIA, 2016, p. 65).

A falta de relação e consistência intradisciplinar origina dificuldades nos processos de ensino e de aprendizagem da Matemática (MARTINS; DIAS, 2017; LORENZATO, 2006), por isso defendemos uma abordagem concomitante de aspectos algébricos, aritméticos e geométricos. $\mathrm{O}$ ensino de Matemática deve estar relacionado com as ligações entre técnicas, procedimentos, fenômenos, conceitos e processos referentes às suas ramificações. O contrário disso limita o ensino de Matemática, tornando-o sem conexão entre suas vertentes, o que resulta na possibilidade de conhecer apenas parte de um todo.

O ensino compartimentalizado que temos nas escolas de Educação Básica atualmente já sofreu uma tentativa de ser unificado. Na verdade, até o início do século XX o ensino de matemática era ainda mais segregado, pois não havia a disciplina de Matemática, e sim as disciplinas geometria, aritmética e álgebra. Embora não tenhamos a pretensão de expor com profundidade a trajetória que o Brasil vem percorrendo na tentativa de trabalhar as ramificações da Matemática de forma concomitante, cabe destacar que tivemos grande influência das ideias difundidas no início do século XX, por Félix Klein na Alemanha.

Klein iniciou uma reforma propondo mudanças no ensino da Matemática por meio da interação entre as suas ramificações, e entre a Matemática e outras áreas do conhecimento (FARIA, 2016; MIRANDA, 2003). Sobre a unificação de aritmética, geometria e álgebra, Klein alegava: "Não quero dizer que essas partes devam ser completamente fundidas, mas não devem ser tão separadas como sucede hoje nas escolas, contra que é natural" (MIRANDA, 2003, p. 74). Para Klein era natural que os ramos da Matemática estivessem relacionados, de modo que não fossem vistos como áreas dissociadas. Por pensar nessas questões, iremos expor uma atividade que, além de apresentar um caráter inter e transdisciplinar, está centrada 
em promover a intradisciplinaridade matemática com tecnologias, buscando apresentar uma possibilidade para o trabalho concomitante entre a aritmética, a geometria e a álgebra na Matemática escolar e evidenciar que o uso do GeoGebra o favorece.

\section{Trabalho intradisciplinar na Matemática escolar com GeoGebra}

A exploração de um conteúdo matemático na perspectiva intradisciplinar é enriquecida se, para tanto, forem disponibilizadas várias formas de representação. Segundo Friendland e Tabach (2001), a aritmética é a que, em geral, precede qualquer outro tipo de representação. É essencial à compreensão inicial de uma situação particular, mas isoladamente não é eficiente para solucionar casos gerais, que valem para todos da mesma natureza, o que a torna, por vezes, limitada. A representação geométrica tem muita relação com a representação intuitiva e até mesmo apelativa. No entanto, ela guarda perigos como a influência de fatores externos, como as escalas e a imprecisão de medições. A representação algébrica, por sua vez, é concisa, geral e efetiva na formalização e análise de padrões e modelos matemáticos. Por outro lado, dispõe de vários símbolos algébricos que podem dificultar a interpretação de resultados (FRIENDLAND; TABACH, 2001).

Uma forma eficiente de trabalhar simultaneamente com essas formas de representação é utilizar o software dinâmico de Matemática, o GeoGebra. Seus diferentes recursos e janelas permitem mostrar os objetos matemáticos nas representações algébrica, aritmética e geométrica, de modo que todas estão dinamicamente conectadas e respondem de forma simultânea e instantânea às alterações realizadas em qualquer uma delas (Figura 1).

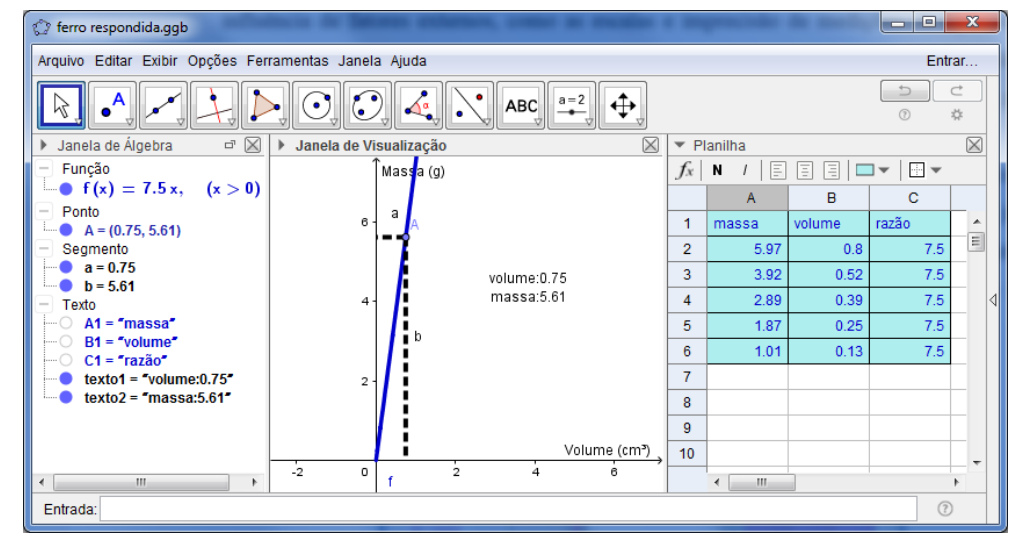

Figura 1 - Tela do GeoGebra com suas janelas de visualização e de álgebra e planilha Fonte: Autores, 2018.

Na janela de visualização é possível realizar variadas construções geométricas. Cada objeto criado na janela de visualização tem também uma representação na janela de álgebra. Assim, ao mover objetos na janela de visualização, é possível perceber que, ao mesmo tempo, 
as suas representações algébricas são atualizadas na janela de álgebra. Também, é possível inserir expressões aritméticas e algébricas na janela de álgebra, usando para isso o campo entrada, e ver a representação geométrica na janela de visualização. Na planilha é possível inserir não somente expressões aritméticas, mas também todo o tipo de expressões algébricas, de modo que a edição das células das planilhas permite a visualização de eventuais representações geométricas e algébricas (REZENDE; PESCO; BORTOLOSSI, 2012).

A Figura 1, por exemplo, é capaz de mostrar como é possível desenvolver e explorar o raciocínio proporcional necessário para o entendimento da relação entre a massa e o volume do ferro, trabalhando simultaneamente os aspectos aritméticos na planilha; aritméticos, geométricos e algébricos na janela de visualização; e aritméticos e algébricos na janela de álgebra. Por meio das três representações concomitantes, o GeoGebra permite que as desvantagens de cada forma de representação sejam compensadas com as vantagens das outras. É nesse sentido que a abordagem que busca desenvolver e explorar o raciocínio proporcional em uma perspectiva intradisciplinar é favorecida por esse software. Ademais, o uso do GeoGebra permite experimentar, criar estratégias, fazer conjecturas, explorar, argumentar e deduzir propriedades matemáticas.

\section{Reflexões sobre a intradisciplinaridade com GeoGebra na Matemática escolar}

Nesta seção, apontaremos algumas de nossas reflexões, envolvendo a análise dos dados que foram produzidos durante um curso realizado com professores de Matemática que atuavam nos Anos Finais do Ensino Fundamental, a partir da interação com os professores, dos questionários de avaliação e dos registros em vídeo e no caderno de campo. As falas dos professores aqui expostas foram extraídas das gravações em áudio e vídeo do curso, dos relatos e dos questionários, contudo, existem interferências nas falas, que foram acrescentadas entre colchetes - [ ] - com o intuito de dar sentido ao trecho para o leitor. Esclarecemos ainda que usamos nomes fictícios para os professores cursistas, de modo a preservar suas identidades.

Com o intuito de evidenciar que o uso do GeoGebra favorece o trabalho intradisciplinar na Matemática escolar, apresentaremos uma análise de trechos da atividade "grandezas proporcionais" que tem por objetivo relacionar grandezas proporcionais e não proporcionais com suas representações aritmética, geométrica e algébrica. Essa atividade é uma das quatro que compõem as atividades de desenvolvimento e exploração do raciocínio 
proporcional propostas em FARIA (2016), que foram disponibilizadas na íntegra na referida tese e também no GeoGebraBook ${ }^{2}$.

As questões iniciais (de 1 a 5) dessa atividade exploram características entre as variáveis x e y, da perspectiva dessas três vertentes matemáticas, que contribuem para a percepção de particularidades que permitem que as grandezas sejam classificadas como diretamente proporcionais, inversamente proporcionais, ou não proporcionais. Tais questões possuem a mesma estrutura. É solicitado que se faça o procedimento inicial (Quadro 1), que indica que os valores da tabela (Figura 2) devem ser digitados na planilha do GeoGebra.

1. Procedimento inicial: no GeoGebra, exiba os eixos e a planilha; digite na planilha os valores indicados na tabela, correspondentes aos de $\mathrm{x}$ na coluna $\mathrm{A}$, e aos de y na coluna B. Selecione os campos que você digitou na tabela, clique com botão direito e vá em: criar $->$ lista de pontos. Ajuste o zoom da janela geométrica para visualizar os pontos marcados. Em seguida, observe o comportamento de $\mathrm{y}$.

Quadro 1 - Enunciado da questão 1 da atividade "Grandezas Proporcionais" Fonte: FARIA (2016).

\begin{tabular}{|c|c|c|c|c|c|c|c|}
\hline $\mathbf{x}$ & 1 & 2 & 3 & 4 & 5 & 6 & 7 \\
\hline $\mathbf{y}$ & 10 & 20 & 30 & 40 & 50 & 60 & 70 \\
\hline
\end{tabular}

Figura 2 - Tabela de valores da questão 1 da atividade "Grandezas Proporcionais" Fonte: FARIA (2016).

Em seguida, uma lista de pontos deve ser criada na janela de visualização, correspondente aos valores da planilha (Figura 3). Criada a lista de pontos, se iniciam alguns questionamentos (Quadro 2) na busca para identificar regularidades. No item $a$, é questionado se algum padrão é perceptível na variação de cada valor de x e de seu respectivo valor y. Ao observar a tabela, é possível perceber, aritmeticamente, que o valor de y é igual a dez vezes o valor de $\mathrm{x}$ em todos os pares ordenados, que são automaticamente criados na janela de álgebra quando a lista de pontos é construída. Geometricamente é possível observar, na janela de visualização, que os pontos estão alinhados. Com a análise desse caso, que tem valores claramente relacionados, ainda nessa parte inicial é possível notar que, algebricamente, as variáveis x e y estão relacionadas pela equação y=10x.

${ }^{2}$ O GeoGebraBook é uma coleção de materiais e folhas de trabalho baseados no GeoGebra. Ele permite a organização de Applets do GeoGebra e materiais em livros online dinâmicos e interativos para aprendizagem e ensino (Fonte: https://www.geogebra.org/m/kC3EpQtS). O GeoGebraBook "Desenvolvendo e explorando o raciocínio proporcional” está disponível em https://ggbm.at/MHSqp4xU. 


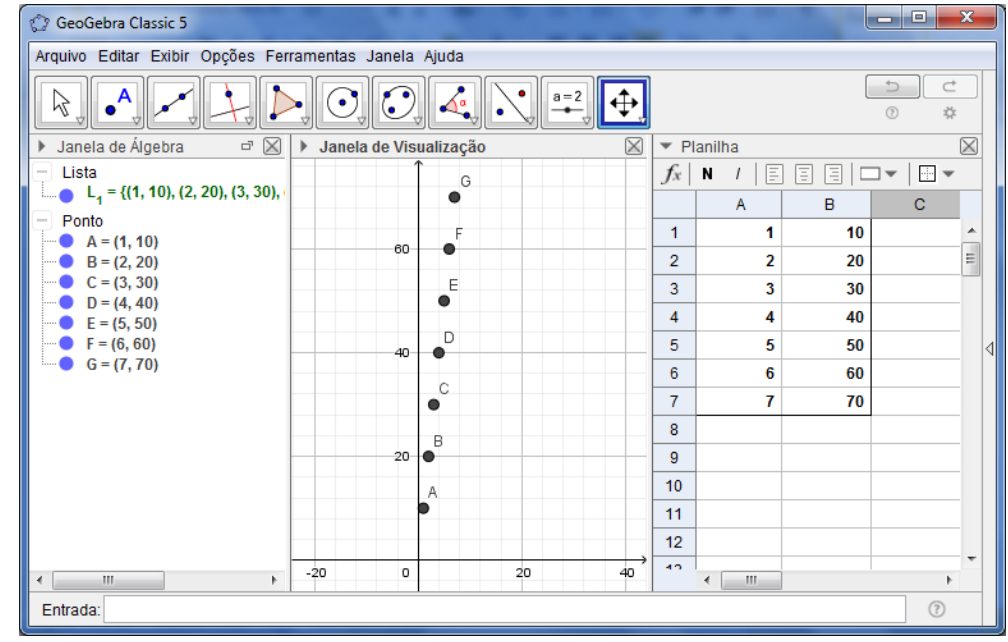

Figura 3 - Lista de pontos na janela de visualização da questão 1 da atividade "Grandezas Proporcionais" Fonte: Autores, 2018.

a. Você consegue observar algum padrão (uma regularidade) na variação dos valores de $\mathrm{x}$ e de seu respectivo valor $\mathrm{y}$ ?

b. Sem fazer cálculos, você diria que x e y são diretamente ou inversamente proporcionais, ou não são proporcionais?

c. Observe os valores em cada linha da planilha. O produto ou o quociente entre eles é constante? Para verificar o que foi perguntado, digite na célula $\mathrm{C} 1 A l * B 1$ e tecle enter, depois selecione $\mathrm{C} 1$ e usando o quadradinho no canto inferior direito da célula copie a fórmula até a linha 7. Repita na célula D1, mas agora digitando $A 1 / B 1$, e copie a fórmula até a linha 7. Resposta: ( ) Sim ( ) Não

d. Baseado nos cálculos realizados, você diria que x e y são diretamente ou inversamente proporcionais, ou não são proporcionais?

Quadro 2 - Itens de $a$ a $d$ da questão 1 da atividade "Grandezas Proporcionais" Fonte: FARIA (2016).

Desde o início da atividade, o uso do GeoGebra favorece a abordagem matemática intradisciplinar. Com os valores numéricos representados aritmeticamente na planilha e simultaneamente representados por pontos na janela de visualização, aspectos concomitantemente relacionados com as três vertentes matemáticas podem ser notados e explorados em uma única tela do GeoGebra. Retomamos a ideia de que a intradisciplinaridade pode facilitar a percepção dos significados dos conceitos, valorizar as semelhanças de cada ramificação da Matemática e agrupar ideias que contribuem para a compreensão de temas matemáticos (LORENZATO, 2006).

Prosseguindo, diante da observação das regularidades, é questionado se já é possível afirmar se x e y são diretamente ou inversamente proporcionais, ou não são proporcionais. Para responder a este questionamento, é necessário ficar atento às observações que foram feitas. $\mathrm{O}$ fato de haver uma relação entre x e y e dos pares estarem alinhados na janela de visualização dá ideia de que há proporcionalidade, embora saibamos que não garanta isso. Nesse sentido, para o item $b$ é esperado uma resposta intuitiva que revele uma primeira impressão. 
No item $c$ alguns testes passam a ser feitos com a intenção de identificar características, como se o produto ou o quociente entre x e y é constante. Identificar se há ou não constante e, em caso afirmativo, verificar se ela é obtida por meio do produto ou do quociente é um passo importante. Haver constante significa que há proporcionalidade na relação entre as variáveis, por isso identifica-las é tão relevante no processo de desenvolvimento e exploração do raciocínio proporcional. Ademais, o fato de a constante ser obtida por meio do produto ou do quociente é o que dá propriedade para distinguir se a relação estabelecida pelos pares ordenados da planilha se trata de grandezas diretamente proporcionais ou de grandezas inversamente proporcionais.

Destacamos ainda que reconhecer que há uma constante aritmeticamente, ou seja, por meio da análise de que há um único valor obtido por meio do produto ou do quociente entre $\mathrm{x}$ e y, é o primeiro passo para determinar uma expressão algébrica que defina a relação entre essas variáveis, e para identificar geometricamente o gráfico capaz de representar a relação entre as grandezas. No que tange a associação do gráfico das grandezas proporcionais (vertente geométrica), com a função que a define (vertente algébrica), bem como com os valores a ela atribuídos (vertente aritmética), dificuldades sempre emergem, pois os alunos não estão habituados a relacionar diferentes formas de representação (FRIENDLAND; TABACH, 2001). Este fato favorece que dificuldades emerjam no que tange a identificação se uma grandeza não é proporcional, ou é direta ou inversamente proporcional, bem como dificulta a elaboração de gráficos (FARIA, 2016).

Embora reconheçamos que não é uma tarefa simples relacionar as vertentes matemáticas, devido ao fato de que essa integração não é habitual aos alunos, nossa experiência nos permite inferir que o GeoGebra se mostrou capaz de contribuir para o desenvolvimento e exploração do raciocínio proporcional em uma abordagem intradisciplinar, como relata a professora:

Miriam: O software GeoGebra proporciona ao aluno a visualização imediata da integração da aritmética, geometria e álgebra facilitando a compreensão e aplicação do conteúdo.

(Questionário, 27/06/2015, FARIA, 2016).

Após os cálculos serem realizados, a pergunta do item $b$ é repetida no item $d$, mas com a intenção de que a ela seja atribuída uma resposta com base nos cálculos realizados. Além da exploração da razão aritmeticamente, cada questão é finalizada com a proposta de dois encaminhamentos diferentes, dentre os quais um deve ser escolhido. Atendendo-se o critério de que no item $c$ foi respondido que há uma constante, devem ser realizados os itens $e$ e $f$ do Quadro 3. Esse item $e$ questiona sobre a expressão que representa y em função de $\mathrm{x}$ nos casos 
em que há razão. Encontrada essa expressão, é pedido no item $f$ para que o gráfico que passa por estes pontos seja construído. Para tanto, a expressão do item $e$ deve ser digitada no campo entrada. A partir de então, deve ser observado qual foi a figura gerada, se ela passa por todos os pontos e pela origem do plano cartesiano $(0,0)$.

Se você respondeu sim na letra $c$, ou seja, que há uma constante, responda:

e. Qual a expressão que representa y em função de $x$ ?

f. Agora, vamos construir o gráfico por estes pontos. Digite a relação encontrada na pergunta anterior na janela de Entrada do GeoGebra. Qual foi a figura gerada? Ela passa por todos os pontos? E pela origem?

Quadro 3 - Primeira parte da finalização da questão 1 da atividade "Grandezas Proporcionais" Fonte: FARIA (2016).

Na construção no GeoGebra da questão 1 (Figura 4) pode ser observado que o gráfico é uma reta cuja expressão que a gerou é $y=10 x$, e que ela passa por todos os pontos e pela origem do plano cartesiano $(0,0)$. Além disso, ao longo da questão foi possível notar que existe constante entre as variáveis x e y da planilha, e que a mesma pode ser encontrada por meio do quociente obtido pelo valor de $\mathrm{x}$ e seu correspondente em y. Embora essa seja uma breve conclusão, ela abarca conceitos e propriedades relacionadas aos aspectos matemáticos intradisciplinares.

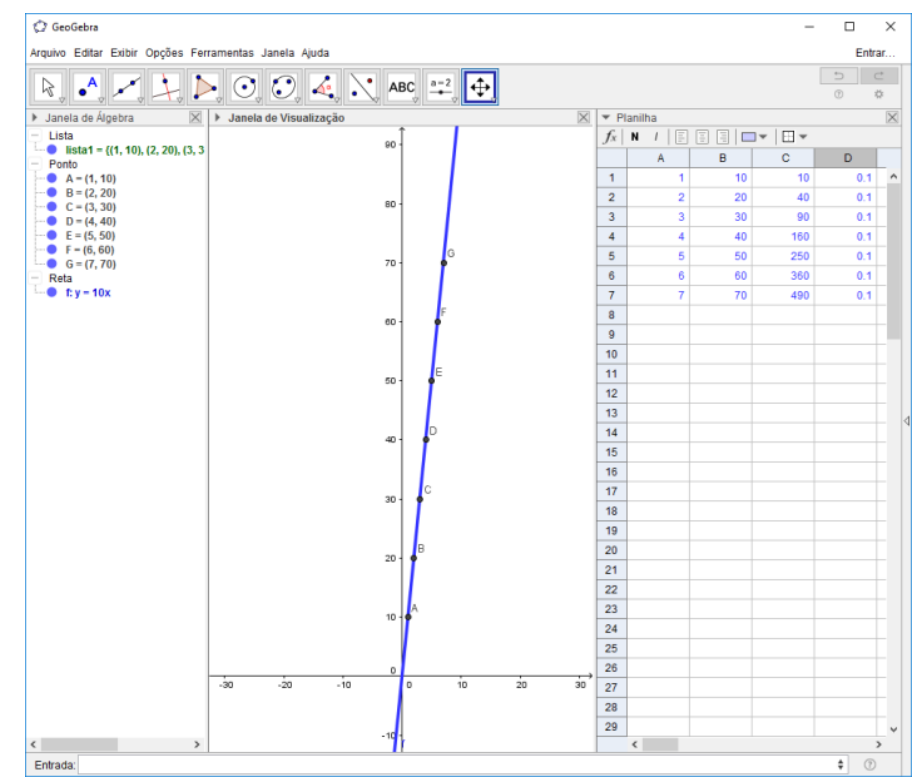

Figura 4 - Tela do GeoGebra com construção da questão 1 da atividade "Grandezas Proporcionais" Fonte: Autores, 2018.

A expressão que define a equação da reta é uma representação algébrica, que compreende todos os pares ordenados que foram representados aritmeticamente na janela de álgebra e geometricamente na janela de visualização. A constante encontrada, definida por uma expressão algébrica e obtida por meio da análise aritmética de cada valor de x e de seu respectivo valor em y, mostrou que há proporcionalidade entre os valores apresentados e se 
tornou ainda mais notável por meio da representação geométrica na janela de visualização, em que foi possível observar que, se a expressão é do tipo $y=a x+b$ com $b=0$, o gráfico é uma reta que passa por todos os pontos analisados e pela origem do plano cartesiano $(0,0)$. Essas características matemáticas intradisciplinares, juntas, permitem afirmar que a primeira questão trata-se de grandezas diretamente proporcionais.

Segundo Lorenzato (2006), integrar aritmética, geometria e álgebra é fundamental para uma compreensão abrangente. $\mathrm{O}$ autor afirma que não se pode entender Matemática em sua totalidade, sem estabelecer conexões entre essas vertentes. E o GeoGebra favorece essas conexões. O professor Davi relatou durante o curso que o GeoGebra colabora para a integração entre a geometria, aritmética e álgebra, de modo a contextualizar as situações de aprendizagem presentes nos materiais didáticos que ele utiliza:

Davi: A integração entre a Geometria, Aritmética e Álgebra que o GeoGebra proporciona, facilita a contextualização das situações de aprendizagens que utilizamos [...]. As atividades propostas enriqueceram o curso (Questionário, 27/06/2015, FARIA, 2016.).

Com a perspectiva intradisciplinar a atividade prossegue. No segundo retângulo (Quadro 4) é apresentado o caminho a ser seguido nos casos em que não há constante. O item $e$ consiste em fazer uma reta passando por dois pontos quaisquer e observar se ela passa por todos os pontos e pela origem do plano cartesiano $(0,0)$. Em caso afirmativo, o item $f$ não deve ser feito. Mas, se não passar em algum ponto, o item seguinte deve ser realizado. O Item $f$ solicita que uma cônica, passando por cinco dos pontos marcados seja construída e, em seguida, seja clicado com o botão direito sobre a expressão da cônica na janela de álgebra para que se observe o nome da curva que foi formada, bem como se ela passa por todos os pontos e pela origem do plano cartesiano $(0,0)$. Finalizando, considerações devem ser registradas para que fiquem evidentes as particularidades matemáticas da questão analisada.

\footnotetext{
Se você respondeu na letra c que não há uma constante, vamos construir o gráfico:

e. Faça uma reta passando por dois pontos quaisquer dos sete que foram criados na janela de visualização. A reta passa por todos os pontos? E pela origem?

Se a reta elaborada no item anterior não passar por todos os pontos, faça o item a seguir:

f. Construa uma cônica passando por cinco desses pontos. Clique sobre a expressão da cônica com o botão direito na janela de álgebra, e diga: qual o nome da curva que foi formada? A Curva passa por todos os pontos? E pela origem?
}

Nessa questão, como foi a expressão que gerou o gráfico? Caso tenha existido razão, com qual equação (colunas $\mathrm{C}$ e $\mathrm{D}$ da planilha) a encontramos? Como podemos descrever o gráfico criado?

Quadro 4 - Segunda parte da finalização da questão 1 da atividade "Grandezas Proporcionais" Fonte: FARIA (2016). 
Registrar como as variáveis se relacionam em uma perspectiva intradisciplinar é necessário para que seja possível identificar se o caso analisado se trata de Grandezas diretamente ou inversamente proporcionais, ou ainda não proporcionais. Nesse sentido, Friendland e Tabach (2001) destacam que a análise de casos aritméticos específicos, o apelo visual da geometria e a capacidade de expressar casos gerais da álgebra devem ser trabalhadas de forma simultânea para que as desvantagens de uma vertente matemática sejam supridas com as potencialidades das outras. Destacamos aqui uma das discussões que ocorreram durante a realização dessa atividade com os professores de Matemática participantes do curso. Ela ocorreu ao final da realização da primeira questão dessa atividade, quando buscamos interpretar o que havia ocorrido no caso que trata de uma grandeza diretamente proporcional:

Rejane: Porque é que tem que passar pela origem? Se não passar pela origem é proporcional ou não é? O que vocês acham disso? Alguém já pensou sobre isso? Vamos tentar pensar em uma situação para aplicar isso, da vida. O que quer dizer passar no zero/zero [No ponto $(0,0)]$ ? [...] Vamos pensar: Uma corrida de táxi é proporcional?

[A turma se divide entre as respostas, mas a maioria diz que é proporcional, e a discussão continua].

Miriam: O que a gente paga é.

Henrique: Não.

Rejane: Quem acha que é, nos diga porque é.

Miriam: Se você andar $20 \mathrm{~km}$ é um valor, se andar $40 \mathrm{~km}$, será outro, proporcional.

Henrique: Mas tem a bandeirada.

Livia: Mas tem a bandeirada, a taxa fixa, não tem?

(Gravação audiovisual, 29/05/2015, FARIA, 2016).

No começo dessa discussão não havia unanimidade na resposta sobre a proporcionalidade do valor pago em uma corrida de táxi. Muitos participaram buscando explicar o seu entendimento da situação. Alguns, mais tímidos, não se manifestavam para todo o grupo, mas, ao analisar o vídeo, é notável que conversavam entre si e, embora não tenha sido possível captar nas gravações o áudio dos que falavam apenas com os colegas ao lado, percebemos que expunham o seu ponto de vista, falando sobre o assunto e gesticulando. Com essa primeira parte da discussão já é possível notar que os professores buscavam exemplificar seus posicionamentos com valores numéricos e com questionamentos. A discussão continuou.

Liliane: Se você andar muito ou andar pouquinho tem aquela taxa fixa. Vamos pensar na ideia da bandeirada, seria somar um $b$ [pensando na equação da reta que é y=ax+b]. Só que se você não andar nada, você não pode falar que você vai pagar aquela taxa.

(Gravação audiovisual, 29/05/2015, FARIA, 2016.).

A fala da professora Liliane indica que, no exemplo da corrida de táxi, ela reconhece a bandeirada como a taxa fixa, o que implica que, aritmeticamente, não haveria alteração do valor a ser pago no que se refere à bandeirada. Quando a professora cita que a bandeirada 
equivale a "somar um b", ela está indicando que a representação algébrica da situação analisada pode ser representada por uma função afim, do tipo $y=a x+b$, o que implica no reconhecimento geométrico da situação, pois apontar que existe um "b" significa que a professora sabe que a representação geométrica da situação é uma reta. A discussão prossegue.

Rejane: Mas se andou $10 \mathrm{~km}$ ou andou $100 \mathrm{~km}$, a bandeirada é a mesma. O que a gente começou a pensar? O que eu pago no táxi é proporcional, ou não é? Não. Por quê? Porque não passa no $(0,0)$. Como assim? Quando eu entro no táxi, ele [o taxista] ligou [o carro] e andou um metro, cobrou a bandeirada. A bandeirada é independente da distância que eu ando. [...] E daí? Por que é que é proporcional ou não? O que é proporcional é o valor pago de acordo com os quilômetros. Isso é proporcional. Agora o valor total que se paga no final [da corrida], não é proporcional, porque não inicia no $(0,0)$. Já existe um valor que é independente da distância. $O$ que faz com que o valor final pago não seja proporcional. E quando eu pensei nisso fez todo sentido pra mim a reta passar no (0,0). Essa reta poderia ser, por exemplo, o valor pago, proporcional à distância percorrida, sem a bandeirada. Mas quando eu adiciono a bandeirada [deixa de ser proporcional].

Liliane: $y=a x+b$, onde bé a bandeirada.

[...]

Henrique: Não, não é proporcional. Se andar um quilometro, você vai pagar quatro reais, mais um real, dá cinco reais [pensando em uma função do tipo $y=4+1 x$, ou seja, a bandeirada sendo quatro reais e um real por quilometro rodado]. Se eu andar dois quilômetros, eu não vou pagar dez reais, vou pagar seis reais. Então não é proporcional.

(Gravação audiovisual, 29/05/2015, FARIA, 2016).

Esse trecho da discussão é iniciado com uma colocação de que, independente da distância percorrida, o valor a ser pago pela bandeirada é o mesmo. Ao interpretar essa situação, é indicado que o valor final da corrida de táxi não é proporcional, pois a bandeirada embutida nesse valor não varia proporcionalmente à distância percorrida, o que faz com que, geometricamente, o gráfico da situação analisada, seja uma reta que passa na origem do plano cartesiano $(0,0)$ e, algebricamente, o $b$ da equação da reta seja, necessariamente, zero. Ainda nesse trecho, durante a fala de Henrique, muitos professores acenam concordando com sua explicação. Os valores numéricos dados pelo professor foram utilizados para explicar que, aritmeticamente, para andar apenas um quilômetro no táxi, seria necessário pagar cinco reais, enquanto que se a distância percorrida dobrar, não acontece o mesmo com o valor a ser pago, ou seja, não será necessário pagar dez reais por dois quilômetros rodados e sim seis reais. A professora Liliane sente a necessidade de esclarecer que, se não houvesse a bandeirada, o valor pago seria diretamente proporcional à distância percorrida.

Liliane: Mas é proporcional ao valor do que vai andar, mais a taxa, a bandeirada.

Rejane: Então, mas o valor final que eu pago, sempre tem a bandeirada. Porque a bandeirada é fixa. Isso faz com que o valor final pago não seja proporcional, independente da distância.

Liliane: Tirando a bandeirada, ele [o valor pago] vai depender de quanto você vai andar.

Henrique: Aí sim, seria proporcional.

Liliane: Então é proporcional ao que vai andar, mais a taxa fixa. 
$[\ldots]$

Rejane: Sim, porque se eu andar $10 \mathrm{~km}$, eu pago quatro [reais] de bandeirada, e se eu andar $100 \mathrm{~km}$, eu pago quatro reais de bandeirada, e não 40 [reais]. É isso que faz com que o resultado não seja proporcional. Vocês conseguiram perceber a relação disso com o $(0,0)$ ? É $o$ ponto de partida. Se existe uma constante, se o b for diferente de zero, não há proporcionalidade. [...] E o que se pode concluir disso tudo? Como é a função de um gráfico de uma grandeza proporcional?

Liliane: $y=a x$

Rejane: Ou $y=a x+b$, com $b=0$. Ou seja, o b tem que ser zero. Não é zero, não é proporcional (Gravação audiovisual, 29/05/2015, FARIA, 2016).

Finalizamos essa discussão quando os professores cursistas indicaram que não havia dúvida sobre os aspectos aritméticos, geométricos e algébricos que classificam as grandezas como diretamente proporcionais. Por meio dessa discussão, argumentamos que a articulação entre os aspectos das vertentes matemáticas é um fator importante para o desenvolvimento matemático (MARTINS; DIAS, 2017). Na fala dos professores é possível notar que as relações entre as vertentes matemáticas e a proporcionalidade não era algo óbvio. Uma professora ao final da discussão dessa atividade chegou a afirmar que

Denise: Com relação às atividades, fiquei muito impressionada com a relação entre proporcionalidade e a origem no plano cartesiano, nunca tinha me dado conta disso e vou aplicar essa novidade em minhas aulas.

(Questionário, 27/06/2015, FARIA, 2016).

Essa atividade prossegue com as questões 2 a 5, que possuem enunciados análogos a questão 1, mas contam com valores diferentes nas tabelas. A questão 2 trata de grandezas inversamente proporcionais, cuja expressão que gerou o gráfico é y=48/x, que existe razão e que foi encontrada por meio do produto entre x e y, e que o gráfico criado pode ser descrito como o ramo positivo de uma hipérbole que passa por todos os pontos e não passa pela origem do plano cartesiano $(0,0)$. A questão 3 trata de grandezas não proporcionais, cuja expressão que gerou o gráfico é $y=2 x+1$, que não existe razão, e que o gráfico criado pode ser descrito como uma reta que passa por todos os pontos, mas não passa pela origem do plano cartesiano $(0,0)$.

Nesta questão foi destacado que passar por todos os pontos é uma condição necessária para ser o gráfico de uma grandeza diretamente proporcional, mas não é suficiente, pois existe a outra condição, que é a reta passar pela origem do plano cartesiano $(0,0)$, como foi discutido na primeira questão. O que significa que esse caso não é proporcional.

A quarta questão trata de grandezas não proporcionais, pois não há razão. A expressão que gerou o gráfico da parábola é $\mathrm{y}=2 \mathrm{x}^{2}$, e ela passa por todos os pontos e pela origem do plano cartesiano $(0,0)$. Por fim, a quinta questão trata de grandezas diretamente proporcionais, cuja expressão que gerou o gráfico é $y=-3 x$, que a razão pode ser obtida por meio do 
quociente entre os valores de x e y e que o gráfico criado é uma reta que passa por todos os pontos e pela origem do plano cartesiano $(0,0)$.

A questão cinco finaliza os exemplos. A atividade conta ainda com a sexta questão, que tem o intuito de relacionar as respostas anteriores, agrupando as características em comum dos gráficos, expressões e valores que caracterizam as grandezas, bem como com duas atividades de aplicação das grandezas proporcionais cuja descrição e análise estão disponíveis em Faria (2016).

Assim como os trabalhos de Lorenzato (2006), Friendland e Tabach (2001) e Faria (2016) defendem, a análise desta atividade evidenciou a importância das representações aritmética, geométrica e algébrica, por meio de questões que abordam, de modo concomitante, estas formas de representação. Ao trabalhar com esses três tipos de representação matemática, é possível adquirir a capacidade de passar de uma forma de representação para outra, o que consideram tão importante quanto reconhecer as particularidades de cada tipo de representação e de ser apto a interpretar as informações apresentadas. Destacamos também o papel desempenhado pelo GeoGebra, que foi reconhecido pelos professores:

Marta: Os nossos alunos possuem uma facilidade de aceitação e uso destas tecnologias, pois já nasceram na era digital e isso torna a aula diferenciada, atrativa e interessante aos olhos deles. A partir deste despertar da curiosidade do aluno, torna-se mais fácil e positivo o uso do GeoGebra, pois é uma ferramenta de fácil utilização e poderá ajudar a compreensão dos conceitos em aritmética, geometria e álgebra.

(Questionário, 27/06/2015, FARIA, 2016).

A abordagem matemática intradisciplinar com o GeoGebra para o desenvolvimento e exploração do raciocínio proporcional que foi apresentada na análise do trecho da atividade possibilita que se tenha uma visão intradisciplinar fundamental ao desenvolvimento abrangente dos conceitos explorados, dando a atenção necessária às particularidades de cada vertente matemática. Nesse sentido, o GeoGebra foi importante para otimizar e viabilizar a abordagem matemática intradisciplinar do raciocínio proporcional, evidenciando características específicas de cada uma dessas vertentes, o que contribuiu para o entendimento do todo, para uma compreensão de conceitos e relações que ocorrem de forma concomitante.

\section{Conclusões}

Embora a menos de 100 anos não havia nem mesmo a disciplina Matemática no Brasil, pois o ensino era compartimentalizado em três disciplinas: aritmética, geometria e 
álgebra, sabemos que ela é uma construção humana composta de descobertas que não foram feitas de forma dissociada. O processo de disciplinarização escolar a separou, de modo que retornar a uma Matemática que tenha coerência, conexão e harmonia entre suas vertentes não é uma tarefa simples. Assim, concordamos que "[...] ou se rompem as grades ou continuamos a ver os nossos alunos e alunas perdidos na divisão disciplinar, sem conseguir religar os conhecimentos de modo a lhes dar sentido" (ALVES; GARCIA, 2000, p. 96).

Buscamos neste artigo discutir o trabalho intradisciplinar na Matemática escolar e trazer evidências de que o uso do GeoGebra o favorece. Em particular, apresentamos a análise de um trecho de uma atividade de desenvolvimento e exploração do raciocínio proporcional com uma abordagem intradisciplinar. A análise realizada permite afirmar que o GeoGebra oportuniza a exploração de múltiplas representações que exaltam particularidades das vertentes da Matemática, por meio de seus diversos recursos e janelas que apresentam os objetos matemáticos nas representações algébrica, aritmética e geométrica, de modo dinamicamente conectados. A possibilidade de exploração simultânea contribui, ainda, para que as desvantagens de cada representação sejam supridas pelas vantagens das outras, no que se refere ao ensino e à aprendizagem de Matemática.

A atividade apresentada com o GeoGebra contribui ainda para que ocorra a experimentação, a criação de estratégias, a produção de conjecturas, a exploração de construções, a argumentação qualitativa e a dedução de propriedades matemáticas relativas à conteúdos matemáticos do Ensino Fundamental, inerentes ao raciocínio proporcional. Assim, a abordagem matemática com GeoGebra ressalta a relevância da intradisciplinaridade e oferece ao professor atividades que permitem que este tipo de exploração seja realizada.

De acordo com Lorenzato (2006), toda a Matemática pode ser apresentada com uma perspectiva intradisciplinar. Nesse sentido, sugerimos que outros trabalhos sejam desenvolvidos em uma perspectiva que integre geometria, aritmética e álgebra com tecnologias digitais, mobilizando para isso conteúdos matemáticos que permeiam toda a Educação Básica. Destacamos ainda que, embora essa atividade tenha sido realizada com GeoGebra para computadores, uma nova versão das atividades de Faria (2016) foi adaptada para celulares e disponibilizada no GeoGebraBook.

\section{Agradecimentos}

Agradecemos os comentários e as sugestões feitas pelos membros do GPIMEM, a versões anteriores deste artigo. 
O presente trabalho foi realizado com apoio do Programa Observatório da Educação, Coordenação de Aperfeiçoamento de Pessoal de Nível Superior - CAPES/Brasil, entidade do Governo Brasileiro voltada à formação de recursos humanos.

\section{Referências}

ALVES, N.; GARCIA, R. L. Atravessando fronteiras e descobrindo (mais uma vez) a complexidade do mundo. In: ALVES, N.; GARCIA, R. L. (Org.). O Sentido da Escola. 2. ed. Rio de Janeiro: DP\&A, 2000. p. 81-110.

D'AMBROSIO, U. A transdisciplinaridade como uma resposta à sustentabilidade. Revista Terceiro Incluído: Transdisciplinaridade e Educação Ambiental, Goiânia, v. 1, n. 1, p. 1-13, jun. 2011.

D’AMBROSIO, U. Uma história concisa da matemática no Brasil. 1. ed. Petrópolis: Vozes, 2008.

FARIA, R. W. S. C. Raciocínio proporcional: Integrando Aritmética, Geometria e Álgebra com o GeoGebra. 2016. 280 f. Tese (Doutorado em Educação Matemática) - Instituto de Geociências e Ciências Exatas, Universidade Estadual Paulista, Rio Claro, 2016.

FRIENDLAND, A.; TABACH, M. Promoting multiple representation in algebra. In: CUOCO, A. A. (Org.). The roles of representation in school mathematics. Reston, VA: NCTM, 2001. p. 173-285.

GALLO, S. Transversalidade e Educação: pensando uma educação não-disciplinar. In: O Sentido da Escola. In: ALVES, N.; GARCIA, R. L. (Org.). O Sentido da Escola. Rio de Janeiro: DP\&A, 2000. p. 17-42.

LAMON, S. Teaching fractions and ratios for understanding: Essential content knowledge and instructional strategies for teachers. 2. ed. Mahwah, NJ: Erlbaum, 2005.

LORENZATO, S. Para aprender matemática. 1. ed. Campinas: Autores Associados, 2006.

MARTINS, L. P.; DIAS, M. A. Os sete aspectos considerados nas tarefas de passagem da Aritmética para a Álgebra. Amazônia - Revista de Educação em Ciências e Matemática, Belém, v. 13, n. 28, p. 90-103. Jul./dez. 2017.

MIRANDA, M. M. A experiência norte-americana de fusão da Aritmética, Álgebra e Geometria e sua apropriação pela educação matemática brasileira. 2003. 98f. Dissertação (Mestrado em Educação Matemática) - PUC, São Paulo, 2003.

MORIN, E. Articular os saberes. In: ALVES, N.; GARCIA, R. L. (Org.). O Sentido da Escola. 2. ed. Rio de Janeiro: DP\&A, 2000. p. 65-80.

REZENDE, W. M.; PESCO, D. U.; BORTOLOSSI, H. J. Explorando aspectos dinâmicos no ensino de funções reais com recursos do GeoGebra. Revista do Instituto GeoGebra Internacional de São Paulo, São Paulo, v. 1, n. 1, p. 74-89, 2012.

Submetido em 05 de Abril de 2018. Aprovado em 21 de Agosto de 2018. 